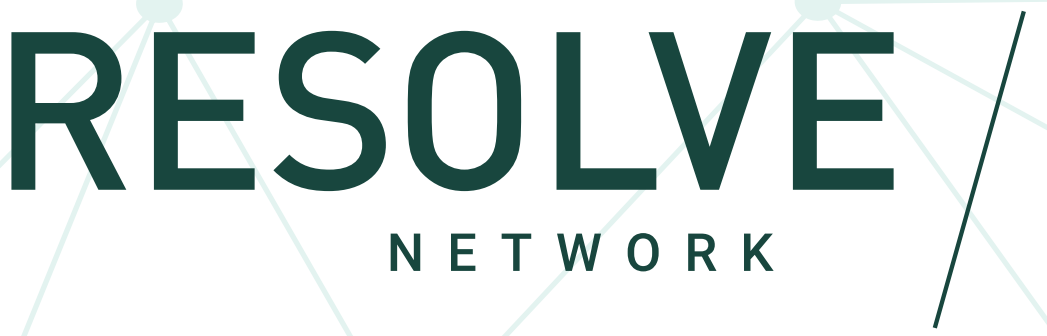

\title{
Getting Local Engagement Right: Key Considerations for Local-level P/CVE Research
} Drew Mikhael \& Julie Norman 


\section{ABSTRACT}

This chapter provides a guide for conceptualizing and conducting community-focused, locally engaged research on preventing and countering violent extremism (P/CVE). Researching P/CVE is especially challenging in conflict zones and divided societies. Local engagement, however, can help researchers gain the trust and access necessary to carry out meaningful qualitative fieldwork. Collaborating with local actors through engagements such as knowledge exchanges and capacity building ensures that research is not purely extractive or transactional. Local engagement builds the foundation for trust between researchers and research participants, which is particularly important when working on P/CVE projects. Furthermore, promoting the exchange of community-based knowledge between researchers and local stakeholders facilitates good ethical practice and enhances conflict sensitivity. Finally, working with local partners increases opportunities for meaningful policy impact, providing insights from real world practices, examples, and case studies that can guide policy development and implementation.

\section{INTRODUCTION}

This chapter presents the case for local engagement in research on violent extremism and delineates best practices from the authors' experiences working with community partners to implement qualitative P/CVE research in Lebanon, Jordan, Iraq, Tunisia, Nigeria, and the United Kingdom (UK). While our experiences are mainly qualitative, local engagement can also improve the cultural and contextual sensitivity of quantitative research efforts, particularly in the development of survey questionnaires. Contextual engagement and sensitivity help navigate sensitive local-level P/CVE research, provide more accurate data, and maintain respectful working relationships between research participants, partners, and the researchers.

Through our own fieldwork, we found that working with local partners was essential in gaining credibility, understanding hyper-local contexts and sensitivities, and accessing under-represented groups, including women, internally displaced persons (IDPs), and refugees. We also found it important to engage with diverse actors within local communities, including former combatants, who are able to offer local experience of historical drivers of violence in their locale. In addition to improving research rigor, local engagement elevates good ethical practice, enhancing conflict sensitivity and researcher responsibility. Finally, we found that engagement with local partners increased opportunities for meaningful policy impact, providing context-relevant examples of best practices for policy and practice.

Local engagement in P/CVE research, however, is not without challenges. Local communities are often reluctant to participate in P/CVE research for fear that research findings will further marginalize local communities and those considered "vulnerable" to recruitment into violent extremist groups. Our experiences underscore the importance of balancing P/CVE research aims on the one hand with the local community's concerns on the other. 
Drawing from our own experience, this chapter encourages researchers to think critically about their research objectives, designs, and implications for both local communities and local, state, and global P/ CVE policies, to facilitate ethically sound research processes and broader impact.

\section{P/CVE RESEARCH: THE IMPORTANCE OF LOCAL ENGAGEMENT}

Preventing and countering violent extremism (P/CVE) has been a key priority for international organizations and research institutes in recent years. ${ }^{1}$ Following the rise of Daesh ${ }^{2}$ in 2014, governments and international institutions have made greater efforts to develop policy responses utilizing evidence-based research to understand, prevent, and combat recruitment by extremist groups worldwide. ${ }^{3}$ Nevertheless, the research underpinning P/CVE policy responses to date have often been based on speculative assertions on the drivers of radicalization and recruitment into violent extremism and the best means to address them.

It is now clear that the search for a singular root cause of violent extremism globally, and even locally, largely misinterprets the problem, leading to oversimplified characterizations and countervailing policy responses that inaccurately and unfairly label certain groups, regions, and classes as more likely to lead to violent extremism. Simplistic responses have furthered alienation and distrust in local communities that should otherwise serve as a vanguard against violent extremism. In addition, donor-led funding streams promoting essentialist understandings of the phenomena decoupled from contextual factors discourage better understanding of violent extremism and the role of local communities.

$\mathrm{P} / \mathrm{CVE}$ research has assumed that there is something new about recent waves of extremism. ${ }^{4}$ This exoticization of violent extremism, however, limits the focus of research and policy to assumption-based options that do not always reflect the dynamics in local contexts. ${ }^{5}$ To address this, it may be helpful to think of P/CVE research as a subset of broader conflict research, blurring the lines between political violence, terrorism, and violent extremism. Research into the causes of violence (including ethnic, regional, national, identity-based, etc.) has produced a significant body of work on the factors leading to violence

1 United Nations General Assembly, "Plan of Action to Prevent Extremism," Report of the Secretary General, December 24, 2015, https:// www.un.org/en/ga/search/view doc.asp?symbol=A/70/674.

2 Da'esh is an Arabic translation of the acronym for the Islamic State in the Levant, also known as ISIL (Islamic State in Iraq and the Levant) or ISIS (Islamic State in Iraq and Syria).

3 Patrick Greenfield, "Home Office Unveils AI Program to Tackle ISIS Online Propaganda," The Guardian, February 13, 2018, https://www. theguardian.com/uk-news/2018/feb/13/home-office-unveils-ai-program-to-tackle-isis-online-propaganda.

4 Arthur Boutellis and Naureen C. Fink, Waging Peace: UN Peace Operations Confronting Terrorism and Violent Extremism (New York: International Peace Institute, 2016) https://www.ipinst.org/wp-content/uploads/2016/10/1610 Waging-Peace.pdf.

5 Radicalisation Awareness Network, “Common P/CVE Challenges in the Western Balkans and European Union," April 4, 2018, https:// ec.europa.eu/home-affairs/sites/homeaffairs/files/what-we-do/networks/radicalisation awareness network/ran-papers/docs/ ran policy practice common pcve challenges sofia 04042018 en.pdf. 
as a reaction to circumstances. ${ }^{6}$ However, factors that influence individual participation in violent political action, including but not limited to violent extremism, require an understanding of hyper-local contexts that manifest in individual perceptions of circumstances. By focusing on local dynamics and perceptions, local engagement and partnerships can help facilitate that understanding and sensitivity for more ethical and accurate research, policy, and practice that contributes to, rather than extracts from, the communities participating in the research process.

\section{OUR EXPERIENCE WITH LOCAL ENGAGEMENT}

Our discussion in this chapter is based on our experiences in Lebanon, Jordan, Iraq, Tunisia, Nigeria, and the UK that underscore the importance as well as the challenges of local engagement in P/CVE research. Our main projects included analyzing responses to radical messaging, examining everyday prevention of radicalization, fostering inter-sectarian cohesion, and assessing the role of exited former fighters in P/CVE interventions.

\section{Responses to Radical and Counter-radical Messaging}

We engaged in a study with Club de Madrid that sought to understand the different reactions to radical and counter-radical messages. ${ }^{7}$ Research for this project took place in 2017 in urban and rural locations in predominantly Sunni communities in Lebanon, Nigeria, and Tunisia. The 522 focus group participants included young people (18-30 years old) and older (30 and above) males and females. Two other focus groups were conducted with a special category of individuals seen as particularly marginalized in the country context, including Palestinian refugees from Ain el Hilweh refugee camp in Lebanon, formerly imprisoned Libyan refugees in Tunisia, and students from a religious school in the North East in Nigeria. Local organizations in each of the three countries worked directly and in collaboration with us to develop and translate the focus group discussion guide, give details on the particular contexts in each country, and recruit participants. The focus groups focused on the consumption and frequency of contact with radical and counter-radical messages and the interpretation and possible behavioral changes the messages would have on participants. The final report was delivered to senior policymakers in each of the case study countries and members of the Club de Madrid network.

6 P/CVE researchers have, after several years of funded research, acknowledged the need for understanding the wider socio-economic and political context and how they contribute to radicalization. See: Lilah El Sayed and Jamal Barnes, Contemporary P/CVE Research and Practice, (Hedayah \& Edith Cowan University, 2017): 8, https://s3-eu-central-1.amazonaws.com/hedavah-wp-offload/hedavah/wp-content/uploads/2019/11/17114200/File-222018131552.pdf.

7 Club de Madrid, "Preventing Violent Extremism: Leaders Telling a Different Story," 2018, http://www.clubmadrid.org/wp-content/ uploads/2017/11/PVE-Outcome-Document-2017-12-1.pdf. 


\section{Everyday Prevention of Radicalization by Local Actors}

We conducted research with the Lebanese Centre for Policy Studies (LCPS) to identify and examine the role of local civil society actors engaged in the prevention of radicalization through everyday engagements. ${ }^{8}$ We conducted semi-structured interviews with local civil society actors just outside of the northern city of Tripoli in Lebanon in the neighborhoods of Bab al Tabbaneh and Jabal Mohsen, which saw significant violence between the Sunni and Alawite communities that lived in the interface areas. For the prominently Sunni area of Bab al Tabbaneh, having seen a significant number of residents leave the area to fight in Syria, the focus of the research was to obtain the views of civil society actors who have worked with those who have been radicalized or those close to them. Since 2015, the conflict has largely dissipated, and the hard security presence in the area has lessened as international, national, and local actors engaged to halt the conflict. The interviews sought to understand what variables made for successful intervention and prevention of young people joining local and regional militias and extremist groups.

\section{Inter-sectarian and Social Cohesion among Young People in Iraq}

We acted as Participatory Action Research (PAR) ${ }^{9}$ consultants on a large European Union and British Council project ${ }^{10}$ designed to increase inter-sectarian social cohesion among youth, especially among those who had suffered communal violence. ${ }^{11}$ We designed a focus group-based study with the recommendations of local experts and partner organizations and delivered qualitative research trainings to the local partner organization responsible for conducting focus groups via a cohort of youth researchers in three provinces in Iraq. In total, 30 focus groups were conducted with 361 total participants across three in areas that had seen significant inter-ethnic violence. We analyzed the data and drew key lessons focusing on interrelated themes of reconciliation in communities.

\section{Evaluation of Formers Effectiveness in Prevention and Exit Work}

We work in a research and professional support capacity for organizations tackling radicalization, including the Lebanon-based NGO Fighters for Peace ${ }^{12}$ and the EU's Radicalization Awareness Network. Our

8 Drew Mikhael, and Julie Norman, "Local Leaders Key to Preventing Violent Extremism among Youth," Lebanese Centre for Policy Studies, March 2019, https://www.lcps-lebanon.org/featuredArticle. php?id=221.

9 Participatory research seeks to enact changes in the community in which it collects data. It typically employs a mixed methods approach and within political science is used to challenge the current social order. For more, see: Orlando Fals Borda, "Participatory (Action) Research in Social Theory: Origins and Challenges," in Handbook of action research, eds. Peter Reason and Hilary Bradbury, (SAGE, 2006), 27-37.

10 To read more on the British Council Hiwar project see here: https://www.britishcouncil.org/partner/international-development/ news-and-events/march-2018/Iraq-the-interplay-between-religion-and-development.

11 The research was recently completed, and the final draft of the report submitted and scheduled to be published.

12 Information on Fighters For Peace can be found here: http://fightersforpeace.org. 
engagements include research, writing evaluation reports on programs, delivering capacity-building trainings, and conducting knowledge exchanges between organizations of former combatants and ex-extremists now working to counter and prevent extremism. Through these engagements, we have observed a number of best practices from various organizations that use approaches to P/CVE in different contexts. We have also conducted semi-structured interviews with key members of different P/CVE organizations to contribute to peer-reviewed articles and public engagement pieces that detail the key lessons to draw to counter radicalization.

\section{LOCAL ENGAGEMENT IN P/CVE RESEARCH: KEY CONSIDERATIONS}

In our work, we have engaged with a variety of actors and partners, including individuals who were involved in violent groups, worked to prevent violence, and were targeted for recruitment by violent actors. While our methods and contexts vary with each project, one consistent element in our approach is engagement at the community or local level. Local engagement, as we define it, means working in neighborhoods and villages and actively engaging participants with direct experience with the radicalization process or practitioners approaching P/CVE from the grassroots level in the research process. Participants, therefore, are not just the subjects of research, they are active contributors to its development and vetting.

Particular challenges arise when conducting local-level P/CVE research, such as gaining access to communities, navigating sensitivities, minimizing risk for vulnerable participants, and extrapolating from local cases to global trends. In our experience, however, meaningful engagement with various local actors can help alleviate some of these challenges, enabling 1) understanding of hyperlocal violent extremism dynamics; 2) access and trust with participant communities; 3) inclusion in the research process and findings; 4) adherence to ethical approaches and standards when conducting research on sensitive and securitized issues; and 5) production of actionable, context-specific, and relevant recommendations for policy/ and practice that are suited to the needs of the community.

Local engagement is not easy. As a research approach, it requires a great deal of commitment and care from researchers to ensure that the research truly engages local communities instead of instrumentalizing them. Based on our own experiences interacting and engaging with local communities to conduct research on sensitive topics, we offer the following recommendations for researchers seeking to conduct local P/CVE studies.

\section{Remember the Bigger Picture}

Local context matters for P/CVE: radicalization most often happens at the individual or small group level. Learning about the perceived deficits in the local context will highlight key methods in recruitment narratives of extremist organizations. Better understanding the grievances behind the narratives will enhance 
policy and programmatic responses that target the underlying drivers of radicalization. However, this local focus should be contextualized within broader, macro level dynamics and policies.

\section{Recognize the Micro-Macro Nexus}

Recent literature indicates that wide generalizations of assumed drivers towards violence or extremism are misplaced, and no single method of prevention works universally. ${ }^{13}$ The weakness of a local engagement approach, especially in P/CVE research aimed at enhancing policy and practice, is that drawing generalizable recommendations becomes difficult. This weakness, turned around, can be a strength, however. While our local engagement approach does not place primacy on national-level P/CVE polices, it recognizes their importance in the local contexts. Much policy understandably focuses on the national level. Our approach seeks to place national-level P/CVE policies in a context of local realities, opening up multiple levels for policy impact and assessing the effect of national-level approaches and dynamics on local experiences.

Inquiring about local-level experiences and relating them to possible P/CVE policies at the national level allows for an intimate and nuanced understanding of the drivers of radicalization in local contexts and the influence (or lack thereof) of broader policies. For example, researching the sectarian interface area of Bab al Tabbaneh and Jabal Mohsen in Tripoli, Lebanon, we found that the motivations for participation in armed groups and the hooks used by recruiters were rooted more in local grievances than in broader religious or political narratives prevalent in other contexts-an important finding when making recommendations for a broader national P/CVE strategy.

While understanding hyperlocal dynamics is essential, researchers must adopt an approach that does not lose the forest for the trees but understands the importance of multiple levels of policy and its influence in local context. One method we found useful to making these connections is grounded theory, which creates theories from emerging patterns in data. Grounded theory allows the salient facts to emerge from the context, providing a better platform for identifying local dynamics that traditional hypothesis-driven research may miss.

\section{FACILITATE Cross-Comparison \& Generalization}

This is not to say, however, that local-engagement approaches cannot build in mechanisms for greater generalizability and cross-comparability. Comparative lessons and synergies between local contexts are important to map out and understand. While localizing research tends to limit the generalizability of findings, this weakness can be mitigated through study designs that allow for comparison through the framing and organization of topics in interviews and focus groups. To collect comparative data across

13 William Stephens, Stijn Sieckelinck, and Hans Boutellier, "Preventing Violent Extremism: A Review of the Literature," Studies in Conflict \& Terrorism (2019), https://doi.org/10.1080/1057610X.2018.1543144; JM Berger, "Making CVE Work: A Focused Approach based on Process Disruption," The International Centre for Counter Terrorism - The Hague, 5 (2016) https://doi.org/10.19165/2016.1.05. 
hyper-local contexts, we recommend formulating and grouping interview and focus group questions thematically, rather than by a context-specific logic.

An example of this approach is our study that compared the perceptions of radical and counter-radical messaging across Nigeria, Tunisia, and Lebanon. To account for the differences in contexts, ensuring hyper-local distinctions while safeguarding the ability to compare the data during the analysis phase, we used the following two questions to guide the focus groups:

- Do these messages impact behavior and how?

- Why do they impact your behavior, why do they not?

Focusing on behavioral changes through interpretative intra-personal understanding of the messages provided a basis for prompts (identified and outlined in the discussion guide testing) to explore the contours of the local context without undermining comparability at a later stage. Further, we employed audio-visual aids, images, speeches, and advertisements, that contained a range of messaging techniques and content. These were specific to each country through particular socio-political messages, content and language but were selected based on over-arching thematic parameters to ensure comparability.

\section{(Actually) Invest in Local Relationships}

Local-level P/CVE research requires building trust between researchers and communities. Local communities and local partners are not only key gatekeepers of access and information, they are experts on local dynamics and efforts. Developing relationships at the local level over time can improve research findings, make the research experience more comfortable for participants, and build lasting, collaborative research practices instead of purely extractive ones. This is particularly true of research in areas affected by conflict and violent extremism, which can be difficult or even detrimental if community members are reluctant to discuss violence or are still suffering from recent trauma.

\section{PARTNer With Local GATEKeEPER}

In our research, we work closely with local partners trusted in their communities. For example, we arranged a focus group with Palestinian refugees from the Ain el Hilweh camp in Lebanon who suffered from a range of formal and informal exclusionary policies of the Lebanese state, making them a vulnerable group wary of conducting interviews with unfamiliar researchers. The border of the refugee camp is securitized by the Lebanese Army, causing the residents of the Ain el Hilweh to be less likely to engage in research focusing on local pathways of radicalization for fear that it might lead to further security protocols. As the local partner had an established relationship with Palestinians in the camp, they could act as an interlocutor, facilitating access to key research participants.

\section{InVESt in MeANingful Relationships \& Exchanges}

The development of good working relationships with grassroots organizations requires a significant investment of time, which the research trip planning stage often omits. Multiple site visits, including ini- 
tial visits without formal data collection, allow researchers to focus on observations and meetings with key individuals and organizations. These visits offer an opportunity for the researcher to obtain access to hard-to-reach participants and to learn about local sensitivities. Offering to contribute pro-bono work in the form of editing funding proposals or final reports can also help cement trusted working relationships with local partners and gatekeepers.

However, while preferable, long-term relationships might not be possible. In these instances, a site visit with key personnel and meetings to outline the parameters of the study to clear any misconceptions are viable alternatives. Allowing the interlocutor organization access to interview questions or initial findings can deepen the research, incorporating suggestions specific to the hyper-local context.

In some cases, we developed long-term partnerships with local organizations that share thematic approaches to tackling violent extremism in different contexts such as Fighters for Peace (FFP), an NGO of ex-combatants in Lebanon, and Small Steps, an organization of former right-wing extremists in the UK. By developing long-term partnerships with both organizations, we have been able to compare and contrast their programmatic approaches to violent extremism longitudinally, which deepened the analysis and accounted for the independent variables between the contexts. Furthermore, as researchers, we were well-placed to communicate best practices to benefit both organizations, especially when funding does not allow for peer knowledge exchanges. This relationship can build trust with individuals inside the organizations, resulting in more access to individuals who are more willing to participate in research, and, ultimately, improving the breadth and inclusivity of the information.

We also have an ongoing relationship with the EU's Radicalisation Awareness Network (RAN) comprised of formers, researchers, and practitioners. Working with this consortium over the long term has enabled us to learn from local partners and act as interlocutors to share best practices between different groups and contexts. Participation in RAN also ensures that as researchers we keep up to date with the current theoretical and empirical developments in the research and practice.

\section{Maintain OBjectivity}

Local engagement for P/CVE research is not without its challenges. For example, as researchers spend more time in communities and develop trust relationships with participants, it may be difficult to maintain objectivity. We address this by striving to include mixed methods in our research designs that allow for triangulation of data that can highlight potential biases. We are also intentional about incorporating

reflexive practice into our methodology, debriefing with each other and with external colleagues about the impact of our presence and our trust relationships on the findings.

\section{Be Inclusive}

Inclusion is not just about seeking participation from the most vulnerable populations (or conceptions of it) but about recognizing the lived experiences and diversity within different populations. For example, while young men have been the primary concern in P/CVE research, focusing research on this group 
alone will not provide the necessary data to understand societal deficits that contribute to marginalization and radicalization. The inclusion of women, girls, and other demographics are crucial to nuance the interrelated phenomena of radicalization, while avoiding broad-stroke assumptions, such as "females are always likely to be a vanguard against extremism."

We strive for inclusion and gender sensitivity in all our conflict-related research, facilitating the inclusion of different socio-political groups into research that stretches beyond, but often informs, the radicalization prism. For example, understanding the issues that coalesce around forced migration and the integration of refugees in new communities highlights a potential pathway of alienation. This marginalization can contribute to group vulnerabilities, which can be instrumentalized to motivate people from those populations to violence. Local engagement helps researchers reach marginalized groups whose voices are often left out of elite-focused or national-level studies and provide underrepresented perspectives that add nuance to P/CVE discussions. Developing trust and building partnerships through local engagement is crucial for accessing marginalized or hard-to-reach groups, including women, youth, refugees or IDPs, and ex-combatants.

\section{ENGAGe Youth}

$\mathrm{P} / \mathrm{CVE}$ research tends to focus on the drivers of radicalization for youth ${ }^{14}$ as the most significant demographic of extremist groups ${ }^{15}$. P/CVE often perceives young people as a problem, labeling young people as vulnerable to radicalization and recruitment. ${ }^{16}$ Youth, however, is not a monolithic grouping. Treating it as such ignores broader, cross-cutting marginalization factors-political, economic, and social-that intersect with other identity factors such as nationality, religion, sect, class, urban or rural livelihood, region, sexual orientation, and race. In environments where young people feel acutely vulnerable, where social pressures limit their engagement in civil life and their autonomy in family settings, research and policies problematizing youth will only serve to alienate them. ${ }^{17}$

For us, ensuring the meaningful representation of young people requires conducting interviews and focus groups with separate age categories. Splitting the so-called youth demographic, ranging from 15 to 35 years, into sub-groups, such as teenagers and young adults 22-35, can elucidate youth perspectives,

14 Elizabeth Pearson, "Why Men Fight and Women Don't: Masculinity and Extremist Violence," Tony Blair Institute for Global Change, September 13, 2018, https://institute.global/policy/why-men-fight-and-women-dont-masculinity-and-extremist-violence.

15 Michael Kimmel, "Almost All Violent Extremists Share One Thing: Their Gender," The Guardian, April 8, 2018, https://www.theguardian. com/world/2018/apr/08/violent-extremists-share-one-thing-gender-michael-kimmel .

16 Merle Verdegaal and Wessel Haanstra, "The Role of Youth Work in the Prevention of Radicalisation and Violent Extremism," Radicalisation Awareness Network, December 7, 2017, https://ec.europa.eu/home-affairs/sites/homeaffairs/files/what-we-do/networks/radicalisation awareness network/about-ran/ran-yf-and-c/docs/ran yf c role youth work prevention radicalisation violent extremism 06-07 122017 en.pdf.

17 For research work that has critically evaluated the negative effect of problematizing young people in different environments, see: Emma C. Murphy, "Problematizing Arab Youth: Generational Narratives of Systemic Failure," Mediterranean Politics 17, no. 1 (2012): 5-22; Peter Kelly, "Youth as an Artefact of Expertise: Problematizing the Practice of Youth Studies in an Age of Uncertainty," Journal of Youth Studies 3, no. 3 (2000): 301-15. 
without seniority causing a reluctance to engage with the questions. As a best practice, we recommend including a cross-section of young people to avoid essentializing certain demographics.

Engaging with young people from different classes, religions, and ethnicities through networks-faith groups, schools, sports and youth clubs-ensures a cross-sectional approach. This avoids treating youth as one broad category and helps to identify issues that affect young people of different backgrounds. For example, in our study in Iraq, refugee youth from minority backgrounds displaced by ISIS had different priorities than university students, and urban youth in Baghdad had different cultural concerns than those in Erbil.

\section{Be Gender Sensitive}

Conflict research in general and P/CVE research in particular often portrays women and girls in a binary, either as victims or saviors. ${ }^{18}$ Many women are indeed victims of extremist violence; Boko Haram abducted 276 schoolgirls in 2014, ${ }^{19}$ and ISIS raped and sexually enslaved thousands of Yazidi women between 2014-2018. ${ }^{20}$ In our research, however, we aim to add nuance to the gender narrative by including women who identify as survivors, activists, community leaders, and ex-fighters. It is good research practice to be sensitive to narratives of masculinity and take a nuanced perspective to men and boys' experiences in conflict as well.

To include gender sensitivity in our research, first, before beginning fieldwork, we include gender sensitivity in the conflict analysis and actor mapping. This inputs a critical gender component into an area of study that has been often male-focused. The use of a gendered view can illustrate if potential failures of masculinity are contributory factors to radicalization and if or how radicalization processes differ between men and women in different contexts. Comparing the process of radicalization across genders and mapping the potential differences in radicalization pathways increases the understanding of the phenomena. Focusing on the hyper-local level helps underscore the gender dynamics within communities that may be particular to the area and guide data collection and data analysis.

Researchers should strive for gender parity through inclusion in the research design to deepen the understanding of an important social dynamic that drives key behavioral patterns. For example, when arranging focus groups, we work with local interlocutors to aim for gender parity. In communities with noted gender sensitivities, we run some focus groups separately with women, ideally with a female facilitator.

18 Amanda Braga and Christina Kwuak, "How Girls' Education Intersects with Violent Extremism," Brookings Education Plus Supplement, April 13, 2017, https://www.brookings.edu/blog/education-plus-development/2017/04/13/how-girls-education-intersects-with-vioo lent-extremism/; For a more nuanced discussion see for example: Yulia Nesterova, "Women and Violent Extremism," Impakter, May 28, 2018, https://impakter.com/women-violent-extremism/; Katherine E. Brown, "Gender and Anti-Radicalisation: Women and Emerging Counter-terrorism Measures," in Gender, National Security, and Counter-terrorism: Human Rights Perspectives, eds. Margaret L. Satterthwaite and Jayne Huckerby (London: Routledge, 2013): 36-59, https://doi.org/10.4324/9780203081396. 
These separate focus groups are often crucial for making women's voices heard and creating a safe space to talk about gender-based violence among other issues.

\section{ENGAGE EX-COMBATANTS}

Though not considered a typical marginalized group, the voices of ex-combatants are often missing from conflict and P/CVE research. ${ }^{21}$ In our work at the local level, especially in Lebanon (with ex-combatants from the civil war) and the UK (with ex-combatants from the Northern Ireland Troubles and former rightwing extremists), we found that the inclusion of formers enhances our research. First, insights from formers are crucial to highlighting the pathways of recruitment and exiting.

Second, in our research we have seen that formers often carry a degree of social capital in their community that can facilitate trust relationships. They are often seen as defenders of communities, having built their reputations through violent political action. They can use their reputations to interact with persons in the process of radicalization who are hard to reach. Formers often have compelling stories and, depending on the individual, the capacity to retell their experience to others and warn against violence as a means to achieve personal goals from a point of authority. In Lebanon, for example, ex-fighters from the civil war worked with youth in the Bab al Tabbeneh and Jabal Mohsen neighborhood to prevent them from being drawn by recruiters to fight in Syria.

Working with formers is not without complications. Finding individuals who have the needed inter-personal capacity but have also sufficiently recovered from their experiences is not always easy. Fully exiting an armed group or ideology can be a years-long process and is not possible for all. With many formers suffering from trauma-related mental health issues, a significant risk of re-traumatization exists if they engage in P/CVE projects before they are ready. There are few formers who are able to engage in activities, and many more are needed to make a meaningful impact. Additionally, in still divided societies, formers who engage publicly in P/CVE or reconciliation work face rejection from their kin-groups. Ongoing deep ethnic enmity and can endanger the former engaging in the P/CVE work and often limits their contributions, in particular public engagements.

Access to former fighters can be difficult, especially in contexts where the conflict is recent or ongoing. ${ }^{22}$ In these cases, we rely on relationships with local NGOs, cultivated through the local engagement approach, to try to gain access to former fighters. Once a trust relationship develops, most former fighters who have exited armed groups welcome the opportunity to engage with researchers to share their experiences and help others disengage or prevent them from joining armed groups.

21 Recent work has pointed to the importance of having former extremists work on prevention and counter radicalization. For more, see: Simon Copland, "How Do You Prevent Extremism," BBC, May 1, 2019, http://www.bbc.com/future/story/20190501-how-do-you-pree vent-extremism?ocid=fbfut\&fbclid=IwAR06gNgznyWscerrIXV7OWSHNI3MeSOILhYifUSWirn240BXXAVa47hJNdU.

22 Liz Sly, "The Jihadists No One Wants," The Washington Post, December 21, 2018, https://www.washingtonpost.com/graphics/2018/ world/syria/isis-prisoners/?utm term=.16fad0e6ae15. 


\section{Be Sensitive}

Local engagement in P/CVE can pose ethical challenges, including 1) undermining the relationship between participants and interlocutors, often through insensitive questioning; 2) jeopardizing the security of participants; 3) and traumatizing participants, particularly those who are more vulnerable (such as young people) or those with direct experience with violence. Establishing cooperative relationships with local organizations enhances good ethical practice and directly feeds into the design of the project, helping phrase questions appropriately and avoid insensitive or traumatizing topics.

\section{Understand \& Prevent Trauma}

In our research, we are mindful that participants can be under significant stress, and insensitive questions or style in qualitative methods can upset or re-traumatize participants. Re-traumatization of participants is a particular risk in conflict areas or with vulnerable groups such as refugees and survivors of sexual violence. The research approach must give participants the space to not answer questions. $\mathrm{P} /$ CVE researchers should diversify data collection methods for conflict sensitivity. Directly quizzing participants during interviews can result in evasion or re-traumatization and can undermine relationships with local partners and participants. Our questions on paper do not ask or inquire about violence-related trauma, although these issues often come up during the focus groups or interviews. It often falls on the researcher to decide to probe further or not; local knowledge and experience in the community can help researchers make that call.

We have conducted interviews with persons whose stories are a matter of public record, and they usually display more comfort with probing questions. However, we have had interviews with former combatants who had sensitive reactions to a memory they recounted-at that point we stepped back from the questions. We have also found value in adopting processes that create co-ownership of interview processes, such as oral-history techniques, which allow the participant to shape the direction of the interview, giving them more agency in determining when and how to discuss difficult topics. These techniques avoid direct challenges on sensitive topics that can lead to participant evasion, disengagement, or traumatization. Other methods we adopted in focus groups were group work exercises-including role plays and privately written stream-of-consciousness activities -in Jordan and Iraq that helped participants open up on the topic and think about the questions in non-linear ways.

\section{Ensure PARTicipant SAFety \& COMfort}

The security of participants is always a priority but is a lead concern in contexts with active state security force operations. Participants fearful of researchers' agendas often did not attend focus groups. We worked with local organizations to develop a one-page description of the research, funding sources, implementers, and the purpose (all repeated before focus groups verbally) to ensure transparent recruitment of participants.

Locations of focus groups and research can be problematic. Significant travel for participants tends to lessen their feeling of security and willingness to participate. We have designed data collection to occur 
in the neighborhoods where participants live, normally on grounds of the local organization or a suitable and neutral safe space. An example that highlights the variance intra country was Iraq; in Baghdad participants were unwilling to meet in hotels due to the history of bombings, while hotels in Erbil were considered safe. We discovered this in conflict analysis discussions before the data collection began.

Displaced people and migrants are some of the most vulnerable groups in society due to the precarity of their legal position and the often-negative response of the host community to their presence. ${ }^{23}$ Refugees have at times been the victim of P/CVE narratives that securitized their presence in host states, identifying them as vulnerable to recruitment, especially those congregated together in camps bordering the states they fled. ${ }^{24}$ As a result, security forces are usually more present in organized camps and on the perimeter governing the spaces where refugees live, which requires researchers to inform local authorities of their project intentions or logistics. To ensure participants' personal security, focus groups can take place away from camps. However, they should convene nearby, as refugees generally restrict their movement to avoid being stopped without documentation.

To increase participant comfort, we have used age brackets and separated genders to ensure that focus group participants felt as comfortable as possible. We obtained the written permission of a parent and legal guardian before engaging participants under the age of 18. In addition, the local partner would provide staff that sat in on the focus groups, ensuring the presence of two adults at all times. We also aim to conduct the interviews or focus groups with facilitators of corresponding genders.

If we are working with local facilitators rather than conducting focus groups ourselves, we work with local partners to select the facilitators and conduct a training, including a mock focus group. We recommend this approach to give facilitators practice in ensuring that participants feel comfortable throughout, especially when answering questions on personal experiences. Most facilitators agreed that the mock focus group helped make them more confident and effective when conducting the actual focus groups.

\section{Protect ANonymity}

P/CVE research should prioritize participants' well-being and anonymity. Researchers must keep all data files and transcripts in a protected repository and guard personally identifiable information of participants to guarantee their safety. When writing up the findings, researchers should only include basic descriptions of gender, age category, or location of province or city to avoid biographical details that could identify participants even without names. The need for these measures increases in states where security apparatuses have a poor human rights record. P/CVE research is likely to draw the attention of security institutions, thus, researchers must take extra care to protect the identity of participants. Local

23 A range of scholarship has concluded that the international structures designed to protect refugees are insufficient. For more, see: Zachary A. Lomo, "The Struggle for Protection of the Rights of Refugees and IDPs in Africa: Making the Existing International Legal Regime Work," Berkeley Journal of International Law 18, no. 2 (2000): 268; Jeff Crisp, "A New Asylum Paradigm? Globalisation, Migration and the Uncertain Future of the International Refugee Regime," St Antony's International Review 1, no. 1 (2005): 39-53.

24 Classic definition of the "warrior refugee" was originally formulated in: Aristide R. Zolberg, Astri Suhrke, and Sergio Aguayo, Escape from Violence: Conflict and the Refugee Crisis in the Developing World (Oxford: Oxford University Press: 1992). 
engagement can help here by making researchers aware of the social context and networks to avoid identifying information and ensuring good ethical and safety practice based on trust relationships.

\section{MANAge Expectations}

Many participants in conflict areas face daily uncertainty of services, such as Syrian refugees in Turkey, Jordan, and Lebanon. Insecurity and the lack improvement in service provision can result in heightened tensions around research. Participants in heavily researched groupings such as Syrian refugees in Lebanon, expressed research fatigue, asking why they should take part in another discussion when they have been involved in many previously. Syrian refugees in the Levant face a near constant turnover of researchers examining socio-political, health, and housing issues they face to-from the perspective of the participants - no discernable benefits in their life. The lack of palpable results in some cases led to anger directed at UN officials during our focus group, often coinciding with cuts in services and support.

One way to ensure a sensitive, ethical approach, is to manage the expectations of research participants upfront, especially when dealing with marginalized local communities. During our research in Lebanon with Syrian and Palestinian refugees, to seek to avoid frustration directed at us or the organizing partner, we sought to manage expectations of participants before the focus group. We gave the partner a clear written script that outlined all the relevant information pertaining to the research to give to the potential participants. We also sought to reduce the inconvenience in the lives of participants by organizing focus groups at locations accessible and times appropriate for them. In south Lebanon, Palestinian residents of the Ain el Hilweh camp had to endure a rigorous security system entering and leaving the camp, and we were denied a permit to enter. To mitigate, we organized a focus group on a day in which the refugees were already visiting the partner adjacent to the camp, reducing additional travel time and stress.

\section{Be Relevant}

There are multiple audiences for P/CVE research findings. It is crucial to be cognizant of the interests of stakeholders on the one hand and the needs of the community on the other. P/CVE has created a research and policy paradigm that has, so far, not managed to properly respond to the multitude of pathways that lead to radicalization. Understanding political violence as an expression of agency related to other potential socio-political marginalization or personal actions (such as drug addiction or suicide) can help to understand individual motivations, communal weaknesses, and policy responses.

Therefore, P/CVE work should create holistic and contextualized research agendas to ensure that the policy recommendations that flow from findings do not paint violent extremism as uniquely abnormal but as a choice in response to the surrounding environment. Policy recommendations should not focus on violent extremism solely but seek to tackle group and individual marginalization. This wider policy focus is essential, as focusing on limiting violent extremism only has already proven to lead to undesirable prescriptions that can target certain groups while constraining healthy public sentiments of dissent that help alleviate feelings of societal alienation. 


\section{Co-Create Policy Recommendations}

Policy recommendations should be inclusive of the grassroots level so that the local dynamics that lead to violence are addressed. Sense-checking findings with partners and participants to ensure that the final report accurately reflects the views and experiences of research subjects helps keep the findings grounded and those who contributed to the research positively engaged. Best practices to sense-check include agreeing with the partner organizations at the start of the project on an appropriate format for reviewing findings, such as sending outlines or drafts for comments, arranging follow-on calls, or returning to the field site to discuss findings and plans for dissemination. During the collaboration over the findings, we develop initial recommendations focused on grassroots interventions with key takeaways that local organizations can implement to increase the efficiency of their P/CVE programming.

\section{Plan fOR Multi-stakeholder Dissemination}

Final reports and recommendations should ensure that the findings speak to important wider trends. Dissemination of the work maximizes policy uptake and should engage participants and local partners in the process when possible. Different stakeholders in regional and international arenas have various levels of influence, so a mapping of key actors can help ensure that the findings reach appropriate audiences and inform relevant program agendas, increasing the likelihood of uptake when presenting the report. For example, the network of Club de Madrid helped gain access to international policymakers and donors interested in P/CVE. During local dissemination, materials should be translated into the local language and disseminated in accessible formats to ensure accessibility and pre-empt bias towards international organizations and donor countries. Building local relationships allows local actors to be involved in the dissemination of findings and implementation of recommendations.

\section{CONCLUSIONS}

From our research, we have found that local engagement tells a more complete story about radicalization processes, taking into account the contexts locals face, including those trying to prevent extremist recruitment and those who have been its targets. We have worked collaboratively with local actors at each stage of the research process to ensure more ethical, inclusive, and contextually appropriate data collection and policy recommendations. This approach is a helpful contrast to top-down P/CVE research that often securitizes common development policy areas, sometimes alienating potential local partners working to confront extremism.

Local engagement for P/CVE research is not without challenges. Overall, however, we find that locally rooted participatory research positively impacts findings. The deep data we uncover via interviews, focus groups, and community case studies conducted with local partners provide a rich picture of how P/CVE operates at the individual and community levels-a necessary complement to top-down large- $\mathrm{N}$ studies.

The challenges of this research are that the qualitative and critical approach is time consuming and that recommendations focusing on an integrated approach tackling marginalization are often deemed 
inappropriate for policymakers who seek an immediate response to violent extremism. However, the methodological approach we have outlined here can help avoid frequent pitfalls of P/CVE research and practice.

A collaborative approach to data collection can create meaningful relationships with practitioners at the grassroots level who are first responders to tackling marginalization. Oftentimes, research does not make use of these key groups and, in worst case, damages relationships with them with research agendas essentializing those who engage in violent extremism. By utilizing established theoretical concepts around violence, violent extremism can be demystified to offer policy prescriptions that do not alienate special categories of people and ensure that the wake of data collection does not undermine relationships with those best placed to tackle violent extremism. 


\section{SOURCES}

BBC News. “Nigeria Chibok Abductions: What We Know." May 8, 2017. https://www.bbc.co.uk/news/world-africa-32299943.

Berger, JM. “Making CVE Work: A Focused Approach based on Process Disruption.” The International Centre for Counter Terrorism-The Hague, 5 (2016) https://doi.org/10.19165/2016.1.05.

Boutellis, Arthur, and Naureen C. Fink. Waging Peace: UN Peace Operations Confronting Terrorism and Violent Extremism. New York: International Peace Institute, 2016. https://www.ipinst.org/wp-content/uploads/2016/10/1610 Waging-Peace.pdf.

Braga, Amanda, and Christina Kwuak. "How Girls' Education Intersects with Violent Extremism." Brookings Education Plus Supplement, April 13, 2017. https:// www.brookings.edu/blog/education-plus-development/2017/04/13/how-girls-education-intersects-with-violent-extremism/.

Brown, Katherine E. "Gender and Anti-Radicalisation: Women and Emerging Counter-terrorism Measures.” In Gender, National Security, and Counter-Terrorism: Human rights perspectives, edited by Margaret E. Satterthwaite and Jayne Huckerby, 36-59. London: Routledge, 2013. https://doi. org/10.4324/9780203081396.

Club de Madrid. "Preventing Violent Extremism: Leaders Telling a Different Story." 2018. http://www.clubmadrid.org/wp-content/uploads/2017/11/PVE-Outcome-Document-2017-12-1.pdf.

Copland, Simon. “How Do You Prevent Extremism.” BBC, May 1. 2019. http://www.bbc.com/future/ story/20190501-how-do-you-prevent-extremism?ocid=fbfut\&fbclid=IwAR06gNgznyWscerrIXV7OWSHNI3MeSOILhYifUSWjrn240BXXAya47hJNdU.

Crisp, Jeff. “A New Asylum Paradigm? Globalisation, Migration and the Uncertain Future of the International Refugee Regime." St Antony's International Review 1, no. 1 (2005): 39-53.

El Sayed, Lilah, and Jamal Barnes. Contemporary P/CVE Research and Practice. Hedayah \& Edith Cowan University, 2017. https://s3-eu-central-1.amazonaws. com/hedayah-wp-offload/hedayah/wp-content/uploads/2019/11/17114200/File-222018131552.pdf.

Fals Borda, Orlando. "Participatory (Action) Research in Social Theory: Origins and Challenges." In Handbook of Action Research, edited by Peter Reason and Hilary Bradbury, 27-37. SAGE, 2006.

Greenfield, Patrick. "Home Office Unveils AI Program to Tackle ISIS Online Propaganda." The Guardian, February 13, 2018. https://www.theguardian.com/ uk-news/2018/feb/13/home-office-unveils-ai-program-to-tackle-isis-online-propaganda.

Kelly, Peter. "Youth as an Artefact of Expertise: Problematizing the Practice of Youth Studies in an Age of Uncertainty." Journal of Youth Studies 3, no. 3 (2000): 301-15.

Kimmel, Michael. “Almost All Violent Extremists Share One Thing: Their Gender.” The Guardian, April 8, 2018. https://www.theguardian.com/world/2018/ apr/08/violent-extremists-share-one-thing-gender-michael-kimmel.

Lomo, Zachary A. "The Struggle for Protection of the Rights of Refugees and IDPs in Africa: Making the Existing International Legal Regime Work." Berkeley Journal of International Law 18, no. 2 (2000).

Mikhael, Drew, and Julie Norman. “Local Leaders Key to Preventing Violent Extremism among Youth.” Lebanese Centre for Policy Studies, March 2019. https:// www.lcps-lebanon.org/featuredArticle.php?id=221.

Murphy, Emma C. “Problematizing Arab Youth: Generational Narratives of Systemic Failure.” Mediterranean Politics 17, no. 1 (2012): 5-22.

Nesterova, Yulia. "Women and Violent Extremism." Impakter, May 28, 2018. https://impakter.com/women-violent-extremism/

Otten, Cathy. "A Broken Homecoming." Foreign Policy, May 2, 2019. https://foreignpolicy.com/2019/05/02/a-broken-homecoming-isis-rape-yazidi/.

Pearson, Elizabeth. “Why Men Fight and Women Don't: Masculinity and Extremist Violence.” Tony Blair Institute for Global Change, September 13, 2018. https://institute.global/policy/why-men-fight-and-women-dont-masculinity-and-extremist-violence.

Radicalisation Awareness Network. “Common P/CVE challenges in the Western Balkans and European Union." April 4, 2018. https://ec.europa.eu/home-affairs/sites/homeaffairs/files/what-we-do/networks/radicalisation awareness network/ran-papers/docs/ ran policy practice common pcve challenges sofia 04042018 en.pdf.

Sly, Liz. "The jihadists no one wants." The Washington Post, December 21, 2018. https://www.washingtonpost.com/graphics/2018/world/syria/ isis-prisoners/?utm term=.16fad0e6ae15.

Stephens, William, Stijn Sieckelinck, and Hans Boutellier. "Preventing Violent Extremism: A Review of the Literature." Studies in Conflict \& Terrorism (2019), https://doi.org/10.1080/1057610X.2018.1543144.

United Nations General Assembly. "Plan of Action to Prevent Extremism.” Report of the Secretary General. December 24, 2015. https://www.un.org/en/ga/ search/view doc.asp?symbol=A/70/674.

Verdegaal, Merle, and Wessel Haanstra. "The Role of Youth Work in the Prevention of Radicalisation and Violent Extremism." Radicalisation Awareness Network, December 7, 2017. https://ec.europa.eu/home-affairs/sites/homeaffairs/files/what-we-do/networks/radicalisation awareness network/ about-ran/ran-yf-and-c/docs/ran yf c role youth work prevention radicalisation violent extremism $06-07122017$ en.pdf. 
Zolberg, Aristide R., Astri Suhrke, and Sergio Aguayo. Escape from Volence: Conflict and the Refugee Cisis in the Developing World. Oxford: Oxford University Press: 1992. 



\section{RESOLVE NETWORK}

better research •informed practice $\bullet$ improved policy on violent extremism.

www.resolvenet.org

(9) in 


\section{RESOLVE /}

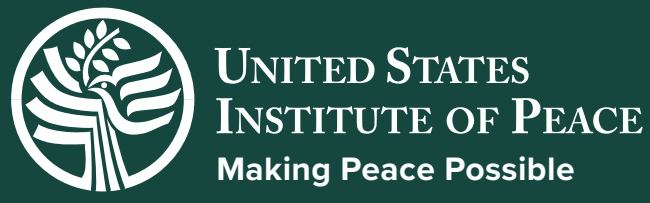

